\title{
Anxiety Depression Stress Scale (ADSS): A Factor Analytic Study
}

\author{
Megha Singh $^{1 *}$, Pallavi Bhatnagar ${ }^{2}$
}

\section{ABSTRACT}

Everyone experiences anxiety, depression and stress at one time or another. Be it educated, professional, students or those living in marginalized existence, for almost all, it is an overwhelming experience predisposing them at times for emotional and psychiatric breakdowns and physical ailment at other point of time. Objective: To explore the factors underlying a scale to assess anxiety, depression and stress (Bhatnagar et.al, 2011). Sample: The factors underlying ADSS were assessed on both psychiatric and non psychiatric patients (972 non-psychiatric and 205 psychiatric individuals). Main Outcomes and Results: The scale developed and used in the present study had 48 items. The principal factoring with VARIMAX rotation yielded 3 factors in anxiety scale viz. physical symptoms, apprehension and dryness of mouth, 2 factors in depression scale viz. inertia-loss of interest and worth and poor emotional control and 2 factors in stress scale i.e. emotional arousal and negative life events. Conclusion: The need of the hour is to gear up efforts for accessibility of mental health services both in terms of screening, as well as, prevention and treatment.

Keywords: Anxiety, Depression, Stress, VARIMAX rotation, Factor Analysis

Stress, depression and anxiety seem to play a major role in today's world. From feeling helpless, lonely and isolated to the crushing exhaustion that makes even the most simple of tasks so very hard, these problems create a living nightmare (Green, 2005).

It seems that anxiety, depression and stress are most often used words in all spheres of life. Since common man uses these words often, they are misinterpreted and misconstrued most of the time. Thus, it becomes imperative to understand that these three are not just psychiatric disorders or states rather they are felt experiences of discomfort and disease varying from person to person.

All of us have experienced some form of anxiety at various points of time in our lives; the sweating palms before the start of an examination; the pounding heart on going to the stage, dryness of mouth while presentations, apprehensions about the future are all features of anxiety. Many patients who are anxious are also depressed, and similarly many patients who are

\footnotetext{
${ }^{1}$ Assistant Professor, Amity Institute of Behavioural and Allied Sciences, Amity University Uttar Pradesh, Lucknow

${ }^{2}$ Professor and Head, Department of Psychology, University of Lucknow

*Responding Author

(C) 2016 I M Singh, P Bhatnagar; licensee IJIP. This is an Open Access Research distributed under the terms of the Creative Commons Attribution License (http://creativecommons.org/licenses/by/2.0), which permits unrestricted use, distribution, and reproduction in any Medium, provided the original work is properly cited.
} 
depressed are also anxious. The close relationship between symptoms of anxiety and those for depression suggests that these disorders may share common etiological features (Hranov, 2007; Garber and Weersing, 2010)

The level of co morbidity between these common problems is substantial, as evidenced by both high correlations between dimensional measures of anxious and depressive symptoms (Cole, Peeke, Martin, Truglio, \& Seroczynski, 1997; Stark \& Laurent, 2001) and diagnostic co morbidity rates as high as $75 \%$ in some clinical samples (Sorensen, Nissen, Mors, \& Thomsen, 2005; Weersing, Gonzalez, Campo, \& Lucas, 2008). In community samples, $25 \%$ to $50 \%$ of youth with depression also meet criteria for an anxiety disorder, whereas only $10 \%$ to $15 \%$ of those with a primary anxiety disorder have a concurrent depressive disorder (Angold, et. al., 1999; Axelson \& Birmaher, 2001; Costello, et. al., 2003). Thus, youth with primary depressive disorders tend to have co morbid anxiety more often than do those with primary anxiety disorders have co morbid depression (Merikangas \& Avenevoli, 2002; Ollendick, Shortt, \& Sander, 2005).

Anxiety is a psychobiological emotional state or reaction and consists of unpleasant feelings of tension, apprehension, nervousness, worry and activation of the autonomic nervous system (Speilberger and Rickman, 1990). Clinical anxiety disorders have been estimated to occur in $5.7 \%$ to $28.8 \%$ of community adolescents (Lewinsohn, et. al, 1993; Costello, 1995; Essau, Conradt, Petermann, 2000). Anxiety, affecting $25 \%$ of the population, is possibly the first stage to the serious-to-handle depression if not addressed (Iyer, 2013).

Depression, in psychiatry, is a symptom of mood disorder (Wolpert, 2000). Depression seriously reduces the quality of life for individuals and their families, is a risk factor for suicide, and often worsens the outcome of other physical health problems. (Worley, 2006). In terms of public health significance, depression is the third leading cause of global disease burden, accounting for $4.3 \%$ of total disability-adjusted life years. If current trends continue, it will become the leading cause of disease burden by the year 2030 (Üstün et.al, 2004; Thirunavukarasu and Thirunavukarasu, 2010).

In Indian context, a recent large sample survey with rigorous methodology reported an overall prevalence of $15.9 \%$ for depression (Poongothai, Pradeepa, Ganesan and Mohan, 2009). There is some suggestion that perhaps the prevalence of depression has increased over past few decades (Nandi, et.al, 2000) Studies done in primary health care settings in India have found depression in 21-84\% of the cases (Amin, Shah and Vankar, 1998; Pothen et.al., 2003). Depression affects $10 \%$ of Indians but day-to-day anxieties are sending more Indians round the bend, say doctors ahead of World Mental Health Day (Iyer, 2013).

Most of us experience stress at one time or another. Without stress, there would be no life. However, excessive or prolonged stress can be harmful. Stress is a condition or feeling 
experienced when a person perceives that "demands exceed the personal and social resources the individual is able to mobilize" (Lazarus, 1966). In short, it's what we feel when we think we've lost control of events. $43 \%$ of all adults suffer adverse health effects from stress. $75-90 \%$ of all patients visits to the physician are for stress related ailments and complaints. Stress is linked to the six leading causes of deaths heart disease, lung ailments, cancer accidents, cirrhosis of the liver and suicide (Salleh, 2008). In times of stress individual may experience depression, worry and anxiety (Campbell, Jamison et.al, 2001; Dorman and Zapf, 2002; Terluin et. al, 2004).

There seems to be a coexistence of anxiety, depression and stress in today's world. Infact both stress and anxiety have theoretically and empirically been found to be so closely linked to performance, drive level that the authors endorse to the statement of Selye (1974) "Complete freedom from stress is death" and that stress and anxiety are as essential for life as blood pressure. It is the excess of both which becomes detrimental and when unable to handle often translate into pathology (i.e. stress disorders or anxiety disorder). On similar notes, depression is the common cold faced by one and all at some point in life however, when it is not handled well it becomes overwhelming and the person experiences clinical symptoms of depressive disorder.

A review of the assessment tools in this context brought forth two major facts. One that there are tools which categorically measure any one of the three anxiety or depression or just stress vizSinha Anxiety Scale (Sinha, 1966), PTSD Checklist- Civilian (PCL-C), Anxiety Scale by Srivastava and Tiwari (1988) etc. The other is that they are leaning more towards a psychiatric assessment facilitating to draw a clinical diagnostic picture viz- Mental Health Inventory by Augustine, PGI Health Questionnaire N-2 by Wig and Verma (1978), CMI Health Questionnaire (Hindi) by Wig, Pershad and Verma (1983) and PGI General Well Being by Verma and Verma (1989).

Anxiety, depression and stress hence are prevalent in all populations, India being no exception, at all ages of life, people from various walks of life, socioeconomic status experience them in varying shades and amount. However, the three are talked about in cognizance together but the assessment of the three in the same tool is scarce with particular reference to India. More so, there was a need of the tool which is bilingual and deals with the needs of illiterate, marginalized and people of below poverty line.

Thus, a need for developing an objective measurement for anxiety, depression and stress was felt by the researcher and Anxiety Depression Stress scale was developed (Bhatnagar et.al, 2011). This tool focuses on the diagnostic criteria of ICD and DSM and covers physical, cognitive, emotional and behavioural symptoms of anxiety, depression and stress disorders. 


\section{METHOD}

\section{Sample}

The sample of the study comprised of 1177 participants (972 non-psychiatric and 205 psychiatric individuals). The sample was covering people from all walks of life. It consisted of 205 psychiatric patients, 376 students, 389 rural people (which is having sample of PWD's also) and 207 slum dwellers.

The psychiatric sample of 205 individual was taken from Sambal Drug De-addiction and Psychiatric hospital, Lucknow; Vivekananda Polyclinic and Institute of Medical Sciences and Sanjeevani Neuropsychiatric Hospital, Lucknow.

In non-psychiatric sample of 972 subjects, 376 (187 male and 189 female) students of P.G. and U. G. from Lucknow University served as urban sample. Besides these measures, a rural sample of 97 (27 female and 70 male) PWD's and 92 (34 female and 58 male) guardians of PWD's from Deva village, District, Barabanki, U.P., and 201 (102 females and 105 males) participants from slums surrounding Lucknow district, U.P. were taken. The age of the sample ranged from 14 to 70 years.

\section{Procedure}

A scale of 63 items was developed (25 items for anxiety, 19 items for depression and stress respectively) in English. After that back translation method was used to translate the items in Hindi with the help of four professionals (two psychologists, one linguist and one social worker) and they were requested to again translate it into English. Those items which maintained the same meaning after the back translation were retained. Thus of the 63 items, 48 items (19 for anxiety, 15 for depression and 14 for stress) which carried similar meaning and context with the original items were retained.

The empirical base of the item was Depression Anxiety Stress Scale by Lovibond and Lovibond (1995), Body Sensation Questionnaire by Chambless, Caputo, Bright and Gallagher (1984), Self Rating Anxiety Scale by Zung (1971), Stanford Acute Stress Reaction Questionnaire by Cardena, Koopman, Waelde and Spiegel (2000), Hamilton Anxiety Rating Scale by Hamilton (1959), Sinha Anxiety Scale (Sinha, 1966), PTSD Checklist- Civilian (PCL-C), Anxiety Scale by Srivastava and Tiwari (1988), Self Reporting Questionnaire (Harding, De Arango, Baltezar et. al., 1980) and General Health Questionnaire (Goldberg and Williams, 1988). Clarity and comprehensibility of the expression was one of the major criterions of development of the items. The self devised ADSS in English and Hindi comprising of 48 items was then administered on a group of 1177 participants (972 non-psychiatric and 205 psychiatric individuals). The scoring of the items was done according to procedure given in the manual (Bhatnagar, et.al, 2011). 


\section{RESULTS}

\section{Interpretation and Identification of factors-}

In identifying factors, the loadings of .30 and above only were considered (Lemke and Wiersma, 1976).

\section{ANXIETY SCALE}

The principal factoring with VARIMAX rotation yielded 3 factors in anxiety scale that are accounted for $43.94 \%$ of total variance. The variance for items of anxiety subscale and Varimax rotation (Table 1 and 2) clearly indicate the dominance of 3 factors which have been named as: Physical Symptoms, Apprehension and Dryness of mouth

TABLE 1: Varimax Rotated Factor loadings for the items of Anxiety Scale

\begin{tabular}{|c|c|c|c|}
\hline \multirow[t]{2}{*}{ Items } & \multicolumn{3}{|c|}{ FACTORS } \\
\hline & I & II & III \\
\hline 1 & .004 & .077 & .878 \\
\hline 2 & .501 & \begin{tabular}{|l|}
.188 \\
\end{tabular} & .270 \\
\hline 7 & .627 & .229 & .083 \\
\hline 11 & .617 & .191 & .152 \\
\hline 14 & .278 & .518 & .067 \\
\hline 15 & .228 & .646 & .029 \\
\hline 18 & .509 & .174 & .100 \\
\hline 20 & .000 & \begin{tabular}{|l|l|}
.786 \\
\end{tabular} & -.046 \\
\hline 21 & .526 & .396 & -.003 \\
\hline 24 & .627 & \begin{tabular}{|l|}
-.001 \\
\end{tabular} & .085 \\
\hline 25 & .573 & .246 & -.120 \\
\hline 28 & .334 & .509 & .147 \\
\hline 32 & .680 & .160 & .034 \\
\hline 34 & .582 & .238 & -.135 \\
\hline 35 & .512 & .218 & -.289 \\
\hline 39 & .455 & \begin{tabular}{|l|}
.358 \\
\end{tabular} & -.129 \\
\hline 41 & .658 & \begin{tabular}{|l|}
.244 \\
\end{tabular} & .003 \\
\hline 45 & .631 & \begin{tabular}{|l|}
.195 \\
\end{tabular} & -.056 \\
\hline 47 & .589 & \begin{tabular}{|l|}
.134 \\
\end{tabular} & -.086 \\
\hline
\end{tabular}


TABLE 2: Factors and their Variance for items of Anxiety subscale

\begin{tabular}{|c|c|c|c|c|c|c|c|c|c|c|}
\hline \multirow[t]{2}{*}{ Factors } & \multicolumn{3}{|c|}{ Initial Eigen values } & \multicolumn{4}{|c|}{$\begin{array}{l}\text { Extraction of Sums of } \\
\text { Squared Loadings }\end{array}$} & \multicolumn{3}{|c|}{$\begin{array}{l}\text { Rotated Sums of Squared } \\
\text { Loadings }\end{array}$} \\
\hline & 尚 & 递 & ১゚ & 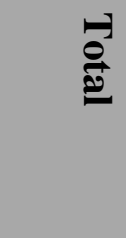 & 总 & $\partial^{0}$ & 㣽 & 苞 & 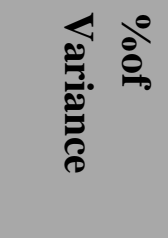 & ১゚ \\
\hline 1 & 6.161 & 32.428 & 32.428 & 6.161 & 32.428 & 32.428 & & 4.971 & 26.161 & 26.161 \\
\hline 2 & 1.155 & 6.081 & 38.509 & 1.155 & 6.081 & 38.509 & & 2.313 & 12.173 & 38.334 \\
\hline 3 & 1.031 & 5.427 & 43.936 & 1.031 & 5.427 & 43.936 & & 1.064 & 5.602 & 43.936 \\
\hline
\end{tabular}

Factor I- Factor I accounts for 26.161\% of variance and explained the maximum proportion of variance in the factor matrix. Items with high loadings on this factor were 'numbness in fingers and toes' (I 32, .680), 'pressure in chest' (I 41, .658), 'blurred vision’ (I 45, .631), 'headaches, neck and back pains and feeling of numbness' (I 24 \& 7, .627), 'faintness' (I 11, .617), 'feeling of nausea’ (I 47, .589), ‘stomachs and indigestion’ (I 34, .582), ‘weak and get tired’ (I 25, .573), 'nervousness and anxious' (I 21, .526), ‘empty bladder often' (I 35, .512), 'difficulty in swallowing' (I 18, .509) and 'difficulty in breathing' (I 2, .501). This factor can readily be identified as Physical Symptoms. An examination of the variables that contributed to the identification of the factor indicates that the highest loading was on items related with exhaustion, pains, nausea, numbness, pressure in chest etc. The participants have reported "I almost always feel tired", "Whenever I am tensed due to work, I feel pain in my body", "I always feel a certain amount of pressure on my chest, it seems to be heavy and pains at times”, "I get tired very easily”. Even the diagnostic criterion give importance to physical symptoms of anxiety and it has emerged as a major factor in this scale.

Factor II- This factor accounted for $12.173 \%$ of variance. The factor had high loadings for items 'unnecessarily worried and panic thoughts or apprehensions' (I 20, .786), 'scared' (I 15, .646), 'heavy perspiration' (I 14, .518) and 'palpitation' (I 28, .509). All the items were related with apprehensions of panic and social blunders, fears, perspirations and palpitations, worrying unnecessarily while heart beating fast. Thus, overall there seems to be dominance of arousal of strong emotions and emotional behavior in which our bodies experience heightened physiological activity and extremes of emotion. Hence, it may be labeled as Apprehension. The participants have reported "Feel scared at night without any reason", "I feel difficulty in taking breath”, "I sweat while sitting”

Factor III- This factor has 5.602\% of variance and had high loadings on only one item that is 'I am aware of the dryness of my mouth' (I 1, .878). Visceral expressions seem to overplay in this factor. As there is no other item, thus it was identified with the name of the item itself viz. Dryness of mouth. 


\section{DEPRESSION SCALE}

The principal factoring with VARIMAX rotation yielded 2 factors in depression scale that are accounted for $46.03 \%$ of total variance. The variance for items of depression subscale and Varimax rotation (Table 3 and 4) clearly indicate the dominance of 2 factors which have been named as: Inertia- loss of interest and worth and poor emotional control

TABLE 3: Varimax Rotated Factor loadings for the items of Depression Scale

\begin{tabular}{|l|l|l|}
\hline \multirow{2}{*}{ Items } & FACTORS & II \\
\cline { 2 - 3 } & I & .135 \\
\hline 3 & .632 & .200 \\
\hline 6 & .648 & .369 \\
\hline 9 & .608 & .412 \\
\hline 10 & .550 & .151 \\
\hline 13 & .632 & -.112 \\
\hline 22 & .591 & .394 \\
\hline 26 & .579 & .235 \\
\hline 27 & .650 & .376 \\
\hline 31 & .646 & .346 \\
\hline 33 & .559 & .347 \\
\hline 37 & .632 & .468 \\
\hline 38 & .252 & .725 \\
\hline 42 & .202 & .726 \\
\hline 44 & .013 & .396 \\
\hline 48 & .504 & \\
\hline
\end{tabular}

TABLE 4: Factors and their Variance for items of Depression subscale

\begin{tabular}{|c|c|c|c|c|c|c|c|c|c|}
\hline \multirow[t]{2}{*}{ Factors } & \multicolumn{3}{|c|}{ Initial Eigen values } & \multicolumn{3}{|c|}{$\begin{array}{l}\text { Extraction of Sums of } \\
\text { Squared Loadings }\end{array}$} & \multicolumn{3}{|c|}{$\begin{array}{l}\text { Rotated Sums of Squared } \\
\text { Loadings }\end{array}$} \\
\hline & 栉 & 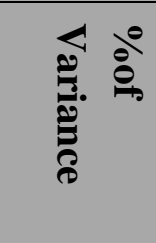 & 。ㅇ & 光 & 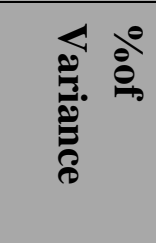 & 。일 & 롤 & 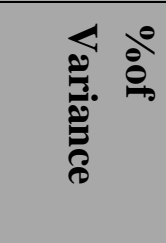 & ১゚ \\
\hline 1 & 5.886 & 39.243 & 39.243 & 5.886 & 39.243 & 39.243 & 4.485 & 29.898 & 29.898 \\
\hline 2 & 1.018 & 6.785 & 46.028 & 1.018 & 6.785 & 46.028 & 2.420 & 16.131 & 46.029 \\
\hline
\end{tabular}

Factor I- This factor accounts for $29.898 \%$ of the variance and the items having high loadings on the factor are 'losing interest in everything' (I 27, .650), 'unable to do anything' (I 6, .648), 'worthlessness' (I 31, .646), 'not able to feel good, not enthusiastic and meaningless' (I 3, 13\& 
37, .632), 'nothing to look forward to' (I 9, .608), 'no initiative' (I 22, .591) and 'feel sad and depressed' (I 26, .579). The factor is being named as Inertia- loss of interest and worth. The items imply an indisposition to change. An inner feeling of being unworthy to do anything and represents the impossibility of behaving in a better way. People reported "There is nothing left in my life", "I do not feel like working”, "Feels heaviness".

Factor II- This factor accounts for $16.131 \%$ of the variance. The items with high loadings on this factor are 'wants to be alone' (I 44, .726), 'crying bouts' (I 42, .725) and 'can't handle/ control feelings' (I 38, .468). This factor basically focuses on the inability to handle the situations, a state of mental agitation often accompanied by physiological changes and lack of sensibility. Thus this factor is being identified as Poor emotional control. The following verbatim were reported by participants "I feel uncomfortable with the changes going on in my life and wants to be alone", "I cry without any reason", "As soon as I am provided with any task, I feel worried thinking that I will not be able to complete the work".

\section{STRESS SCALE}

With the help of principal factor analysis method two factors emerged in the stress subscale. These factors are covering $39.19 \%$ of the total variance. The variance for items of stress subscale and Varimax rotation (Table 5 and 6) clearly indicate the dominance of 2 factors which have been named as: Emotional arousal and Negative life events.

TABLE 5: Varimax Rotated Factor loadings for the items of Stress Scale

\begin{tabular}{|l|l|l|}
\hline \multirow{2}{*}{ Items } & FACTORS \\
\cline { 2 - 3 } & $\mathbf{1}$ & $\mathbf{2}$ \\
\hline 4 & .433 & .163 \\
\hline 5 & .600 & .213 \\
\hline 8 & .335 & .443 \\
\hline 12 & .662 & .149 \\
\hline 16 & .730 & .064 \\
\hline 17 & .567 & .300 \\
\hline 19 & .508 & .162 \\
\hline 23 & .445 & .365 \\
\hline 29 & -.023 & .683 \\
\hline 30 & .168 & .684 \\
\hline 36 & .371 & .562 \\
\hline 40 & .274 & .540 \\
\hline 43 & .243 & .565 \\
\hline 46 & .204 & .575 \\
\hline
\end{tabular}


TABLE 6: Factors and their Variance for items of Stress subscale

\begin{tabular}{|c|c|c|c|c|c|c|c|c|c|c|c|}
\hline \multirow[t]{2}{*}{ Factors } & \multicolumn{3}{|c|}{ Initial Eigen values } & \multicolumn{4}{|c|}{$\begin{array}{l}\text { Extraction of Sums of } \\
\text { Squared Loadings }\end{array}$} & \multicolumn{4}{|c|}{$\begin{array}{l}\text { Rotated Sums of Squared } \\
\text { Loadings }\end{array}$} \\
\hline & 苞 & 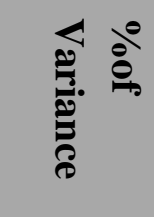 & ১゚ & 苞 & 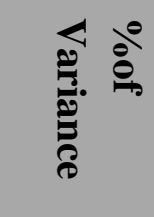 & $\begin{array}{l}0 \\
0\end{array}$ & 导 & 車 & 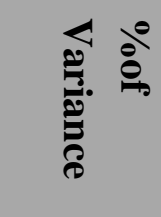 & $\begin{array}{l}0 \\
\partial^{0}\end{array}$ & 尽 \\
\hline 1 & 4.360 & 31.146 & 31.146 & 4.360 & 31.146 & 31.146 & & 2.752 & 19.654 & 19.654 & \\
\hline 2 & 1.127 & 8.048 & 39.194 & 1.127 & 8.048 & 39.194 & & 2.735 & 19.539 & 39.193 & \\
\hline
\end{tabular}

Factor I- Factor I accounts for $19.654 \%$ of the variance. The items with high loadings on this factor are ‘more irritable' (I 16, .730), ‘touchy' (I 12, .662), 'get upset easily' (I 5, .600), 'find it hard to calm down' (I 17, .567), 'difficult to tolerate interruptions in what I am doing' (I 19, .508), 'agitation' (I 23, .445) and 'difficult to relax' (I 4, .433). This factor is identified as Emotional arousal as it includes more of bodies experience, heightened physiological activity and extremes of emotion. The verbatim of the subjects include statements like "Even small things offend me”, "Once I am angry it becomes difficult to calm down”, "If someone says anything I feel irritated"

Factor II- This factor accounts for $19.539 \%$ of the variance and items that have high loadings on this factor include 'extremely upset if exposed to similar events or reminded of similar events' (I 30, .684), 'slow to respond' (I 29, .683), 'difficulty in concentration' (I46, .575), 'problems in relationships' (I 43, .565), 'repeated unwanted memories of the stressful event' (I 36, .562), 'mind goes blank' (I 40, .540) and 'restless if delayed' (I 8, .443). The items indicate a preoccupation of negative memories and hence the factor is being named as Negative life events. The participants reported "I am unable to handle my relationships, feel stressed at times", "I am unable to concentrate on even important things at times", "Only old memories revolve around my mind”.

\section{DISCUSSION}

Thus, the principal component analysis of the variables suggests that in ADS scale 7 factors have emerged (1) Physical symptoms, (2) Apprehension and (3) Dryness of mouth (in anxiety subscale) (4) Inertia- loss of interest and worth and (5) Poor emotional control (in depression subscale) (6) Emotional arousal and (7) Negative life events (in stress subscale).

The factors having high loadings on the scale have considerable similarity with one another and are the dominant features of an individual's life. Factor I "Physical symptoms", Factor II “Apprehension” and Factor III "Dryness of mouth” are clearly indicating the dominance of criteria and symptoms of anxiety across the life span of the individual. It has been found that the rapid heartbeat, trembling, shaking, apprehension, restlessness, sweating are the key features of anxiety (Carson, Butcher and Mineka, 2003; RC Psych, 2008 a; RC Psych 2010 b; APA, 2010; Claringbul, 2011; Sadock, Sadock and Ruiz, 2015) and the same has emerged as factors with 
high loadings. Besides, there is a belief that physical activity and exercise have positive effects on mood and anxiety (Strohle, 2009; Carke, Laibstain and Carke, 2011). Thus, the three factors of anxiety have a common function and relation with the physiological activity and emotional turmoil of people.

The factors related to depression emerged as "Inertia-loss of interest and worth" (Factor I) and poor emotional control (Factor II). Most of the participants reported that they do not enjoy doing their work, their life seems meaningless and they do not take initiative to do any work. The diagnostic criteria of depression also focus on the hopelessness towards future. However, researchers have reported to differentiate clinical depression from these more ubiquitous transient negative mood states (Sadock, Sadock and Ruiz, 2015).

Another important aspect is that most of the time co morbidity is reported among anxiety and depression but the different factors have emerged in the two constructs. This also highlights the fact that though one may affect the other but their etiology, consequences and treatments are different and they cannot be measured and assessed under one head. Bares et.al. (2011) have also given similar findings where they found out that anxiety and depression constructs have similar emotional features and, despite sharing a common underlying internalizing disorder, distinct items capture aspects of each construct.

For stress the factors of high loadings are emotional arousal and negative life events. Participants have reported difficulty in tolerating interruptions, difficulty in calming down themselves, feeling agitated, preoccupation with the thoughts of negative life events, problems in their relationships etc. The factor of emotional arousal of stress is somewhat similar to the factor of poor emotional control of depression. Therefore, the researchers believe that stressful life events are known to contribute to development of depression; however, it is possible this link is bidirectional (Philips, Carroll and Der, 2015; Hammen, 2005). Stress is believed to be the most important determinant of depression which is clearly reflected by the two factors emerged in the subscale of stress.

Thus, with the help of the present study the major components of anxiety, depression and stress are identified. On the basis of these factors the prevention and intervention plans for the individuals suffering from anxiety, depression and stress could be reduced.

\section{REFERENCES}

American Psychiatric Association. (2010). Diagnostic and Statistical Manual of Mental Disorders. 4th ed, text rev. Washington, DC: American Psychiatric Association.

Amin, G., Shah, S., Vankar, G.K. (1998). The prevalence and recognition of depression in primary care. Indian J Psychiatry, 40, 364-39.

Angold, A., Costello, E. J., Erkanli, A. (1999). Comorbidity. Journal of Child Psychology, Psychiatry, and Allied Disciplines, 40, 57-87. 
Augustine, Mental Health Inventory. In D.M. Pestonjee (Ed.) (1988) Second Handbook of psychological and Social Instruments, New Delhi: Concept Publishing Company.

Axelson, D. A., Birmaher, B. (2001). Relation between anxiety and depressive disorders in childhood and adolescence. Depression and Anxiety, 14, 67-78.

Bares, C. B., Andrade, F., Delva, J. \& Grogan-Kavlor, A. (2011). Examining the Factor Structure of Anxiety and Depression Symptom Items Among Adolescents in Santiago, Chile. J Soc Social Work Res, 2(1), 6332.

Bhatnagar, P., Singh, M., Pandey, M., Sandhya, Amitabh. (2011). Manual for anxiety, Depression and Stress Scale. National Psychological Corporation.

Campbell-Jamison, F.; Worral, L. \& Cooper, C. (2001). Downsizing in Britain and its effect on survivors and their organizations. Anxiety, Stress and Coping, 14, 35-58.

Cardena, E., Koopman, C., Classen, C., Waelde, L.C. \& Spiegel, D. (2000). Psychometric Properties of the Stanford Acute Stress Reaction Questionnaire: A Valid and Reliable measure of Acute Stress. Journal of Traumatic Stress, 13, 719-734.

Carek, P.J., Laibstain, S. E., Carek, S. M. (2011). Exercise for the treatment of depression and anxiety. Int. J. Psychiatry Med, 41 (1), 15-28.

Carson, R. C., Butcher, J. N., \& Mineka, S. (2003). Abnormal psychology and Modern Life. New Delhi: Pearson Education.

Chambless, D.L., Caputo, G.C., Bright, P. \& Gallagher, R. (1984). Assessment of 'fear of fear' in Agoraphobias. The Body Sensation Questionnaire. Journal of Consulting and Clinical Psychology, 52, 1090-1097.

Claringbul, N. (2011). Mental Health in counseling and Psychotherapy. Great Britain: Learing Matters.

Cole, D. A., Peeke, L. A., Martin, J. M., Truglio, R., Seroczynski, A. D. (1997). A longitudinal look at the relation between depression and anxiety in children and adolescents. Journal of Consulting and Clinical Psychology,106, 586-597.

Costello, E. J., Mustillo, S., Erkanli, A., Keeler, G., Angold, A. (2003). Prevalence and development of psychiatric disorders in childhood and adolescence. Archives of General Psychiatry, 60, 837-844.

Costello, E.J., \& Angold, A. (1995). Epidemiology. In John March (Ed.), Anxiety disorders in children and adolescents (pp. 109-124). New York: Guilford.

Dormann, C., \& Zapf, D. (2002). Social Stressors at Work, Irritation, and Depressive Symptoms: Accounting for Unmeasured Third Variables in a Multi-Wave Study. Journal of Occupational and Organizational Psychology, 75, 33-58.

Essau, C. A., Conradt, J., Petermann, F. (2000). Frequency, comorbidity, and psychosocial impairment of anxiety disorders in German adolescents. Journal of Anxiety Disorders, 14, 263-279

Garber, J. \& Weersing, V. R. (2010). Comorbidity of Anxiety and Depression in Youth: Implications for Treatment and Prevention. Clin Psychol, 17(4), 293-306.

Goldberg, D., Williams, P. (1988). A User's Guide to the General Health Questionnaire Windsor: NFER-Nelson. 
Green, C. (2005). Conquering stress, e-book.

Hamilton, M. (1959). The Assessment of Anxiety States by Rating. British Journal of Medical Psychology, 32, 50-55.

Hammen, C. (2005). Stress and depression. Annual Review of Clinical Psychology, 1, 293-319.

Harding, T.W., De Arango, M.V., Baltazar J., et.al. (1980). Mental Disorders in Primary Health Care: A Study of their Frequency and Diagnosis in four developing countries. Psychological Medicine, 10, 231-41.

Hranov, L. G. (2007). Comorbid anxiety and depression: illumination of a controversy. International Journal of Psychiatry in Clinical Practice, 11(3), 171_189.

Iyer, M. (2013). One of every four Indians affected by anxiety disorders, $10 \%$ are depressed. The Times of India. Retrieved from http://timesofindia.indiatimes.com/home/science/One-ofevery-four-Indians-affected-by-anxiety-disorders-10-are-

depressed/articleshow/23599434.cms

Lazarus, R.S. (1966). Psychological stress and the coping process. New York: McGraw-Hill.

Le'pine, J.P. (2002). The epidemiology of anxiety disorders: prevalence and social costs. Journal of Clinical Psychiatry, 63 (14), 4-8.

Lemke, E. \& Wiersma, W. (1976). Principles of Psychological Measurement. Chicago: Rand McNally College Publications.

Lewinsohn, P. M., Hops, J., Roberts, R. E., Seeley, J. R., \& Andrews, J. A. (1993). Adolescent psychopathology: I. Prevalence and incidence of depression and other DSM-III-R disorders in high school students. Journal of Abnormal Psychology, 102, 133-144.

Lovibond, P.F. \& Lovibond, S.H. (1995). The Structure of Negative Emotional States: Comparison of the Depression Anxiety Stress Scales (DASS) with the Beck Depression and Anxiety Inventories. Behaviour Research and Therapy, 33: 335-343.

Merikangas, K., Avenevoli, S. (2002) Epidemiology of mood and anxiety disorders in children and adolescents. In: Tsuang, M. T., Tohen, M., (Eds.). Textbook in Psychiatric Epidemiology. (pp. 657-704) New York, NY: Wiley.

Murray, C.J.L., Lopez, A.D. (1996). The Global Burden of Disease. Geneva, WHO, Harvard School of Public Health, World Bank.

Murray, C.J.L., Lopez, A.D. (1998). The Global Burden of Disease Series. Harvard University Press, Cambridge.

Nandi, D. N., Banerjee, G., Mukherjee, S. P., Ghosh, A., Nandi, P. S., Nandi, S (2000). Psychiatric morbidity of a rural Indian community changes over a 20 year interval. British J Psychiatry; 176, 351-6.

Ollendick, T. H., Shortt, A. L., Sander, J. B. (2005). Internalizing disorders of childhood and adolescence. In: Maddux, J. E., Winstead, B. A. (Eds.). Psychopathology: Foundations for a contemporary understanding. (pp. 353-376) Mahwah, NJ: Lawrence Erlbaum.

Patel, V. (1996). Recognizing Common Mental Disorders in Primary Care in African Countries: Should'Mental' be Dropped? Lancet, 347, 742-744.

Patel, V., Todd, C.H., Winston, M., et, al. (1998). The Outcome of Common Mental Disorders in Harare, Zimbabwe. British Journal of Psychiatry, 172, 53-57. 
Philips, A. C., Carroll, D., \& Der G. (2015). Negative life events and symptoms of depression and anxiety: stress causation and/or stress generation. Anxiety Stress Coping, 28 (4), 35771.

Poongothai, S., Pradeepa, R., Ganesan, A., Mohan, V (2009). Prevalence of depression in a large urban South Indian population - The Chennai Urban Rural Epidemiology Study (CURES-70). PloS One, 4, 7185.

Pothen, M., Kuruvilla, A., Philip, K., Joseph, A., Jacob, K. S. (2003). Common mental disorders among primary care attenders in Vellore, South India: Nature, prevalence and risk factors. Int J Soc Psychiatry, 49, 119- 25.

RC Psych (Royal College of Psychiatrist (2008 a). Depression. London: RC Psych, Public Education Board.

RC Psych (Royal College of Psychiatrist (2010 b). Anxiety and Phobias. London: Public Education Editorial Board.

Sadock, B. J., Sadock, V. A., \& Ruiz, P. (2015). Synopsis of Psychiatry. New Delhi: Wolters Kluwer.

Salleh, M. R. (2008). Life event, stress and illness. Malays J Med Sci, 15(4), 9-18.

Selye, H. (1974). Stress without distress. Philadelphia: J. B. Lippincott.

Sinha, D.N. (1966). Sinha Anxiety Scale. In D.M. Pestonjee (Ed.) (1988) Second Handbook of psychological and Social Instruments, New Delhi: Concept Publishing Company.

Sorensen, M. J., Nissen, J. B., Mors, O., Thomsen, P. H. (2005). Age and gender differences in depressive symptomatology and comorbidity: An incident sample of psychiatrically admitted children. Journal of Affective Disorders,84, 85-91.

Spielberger, C. D. \& Rickman, R. L. (1990). Assessment of State and Trait Anxiety in Cardiovascular Disorders. In D.G Byrne and R.H. Rosenman (Eds.). Anxiety and the hearts (pp. 73-92).New York: Hemisphere Publishing Corporation.

Srivastava, D.N. \& Tiwari, G (1988). Anxiety Scale. In D.M. Pestonjee (Ed.) (1988) Second Handbook of psychological and Social Instruments, New Delhi: Concept Publishing Company.

Stark, K. D., Laurent, J. (2001). Joint factor analysis of the children's depression inventory and the revised children's manifest anxiety scale. Journal of Clinical Child Psychology, 30, 552-567.

Strohle, A. (2009). Physical activity, exercise, depression and anxiety disorders. J Neural Transm, 116 (6), 777-84.

Terluin, B., van Rhenan, W., Schaufeli, W. B., \& de Haan, M. (2004). The Four Dimensional Symptom Questionnaire (4DSQ): Measuring distress and other mental health problems in a working population. Work \& Stress, 18(3), 187-207.

Thirunavukarasu, M., Thirunavukarasu, P. (2010). Training and National deficit of psychiatrists in India - A critical analysis. Indian J Psychiatry, 52, 83-8.

Üstün, T.B., Ayuso-Mateos, J.L., Chatterji, S., Mathers, C., Murray, C. J. L. (2004). Global burden of depressive disorders in the year 2000. British Journal of Psychiatry, 184, 38692. 
Verma, S.K. \& Verma, A. (1989). PGI General Well-Being Measure. Ankur Psychological Agency.

Weersing, V. R., Gonzalez, A., Campo, J. V., Lucas, A. N. (2008) Brief behavioral therapy for pediatric anxiety and depression: Piloting an integrated treatment approach. Cognitive and Behavioral Practice 15, 126-139.

Wig, N.N. \& Verma, S.K. (1978). PGI Health Questionnaire N-2. In D.M. Pestonjee (Ed.) (1988) Second Handbook of psychological and Social Instruments, New Delhi: Concept Publishing Company.

Wig, N.N., Pershad, D., Verma, S.K. (1983). CMI Health Questionnaire (Hindi). National Psychological Corporation.

Wolpert, M.M. (2000). The Columbia Electronic Encyclopedia Copyright (C) 2004. Licensed from Columbia University Press.

Worley, H. (2006). Myriad Obstacles-Particularly Stigma-Block Better Treatment in Developing Countries. Population Reference Bureau.

Zung, W.W.K. (1971). A Rating Instrument for Anxiety Disorders. Psychosomatics, 12, 371-379. 